\title{
Risk Factors for Acute Otitis Media in Children Aged 0 to 5 Years in Parakou
}

\author{
Spero H. Raoul Hounkpatin 1*, Julien Didier Adedemy1, Marius C. Flatin1, \\ Senami Florine E. Awassi' ${ }^{1}$, Sonia Lawson Afouda², François Avakoudjo², \\ Wassi Adjbabi², Sogbadji J. Vodouhè ${ }^{2}$ \\ ${ }^{1}$ Faculty of Medicine, University of Parakou, Parakou, Benin \\ ${ }^{2}$ Faculy of Health Sciences, University of Abomey-Calavi, Cotonou, Benin \\ Email: "speraoul@yahoo.fr
}

Received 19 January 2016; accepted 8 March 2016; published 11 March 2016

Copyright (C) 2016 by authors and Scientific Research Publishing Inc.

This work is licensed under the Creative Commons Attribution International License (CC BY).

http://creativecommons.org/licenses/by/4.0/

(c) (i) Open Access

\begin{abstract}
Introduction: Acute otitis media (AOM) is one of the most common ENT childhood diseases. Objective: To identify risk factors for AOM in children aged 0 to 5 years. Methods: This research work was a cross-sectional, descriptive and analytical study. It focused on 2040 children aged 0 to 5 years from both sexes, who were healthy or sick, and living in the Local government of Parakou for at least one year. Those children were randomly selected in all three districts of Parakou. Results: Frequency of AOM was $2.8 \%$ and their prevalence was estimated at $16.3 \%$. The identified risk factors were persistent or chronic cases of rhinitis, exposure to charcoal and wood smoke, low socioeconomic status, personal history of $\mathrm{AOM}, \mathrm{AOM}$ history among the siblings, and children's poor nutritional status. No relationship could be established between AOM occurrence and factors like sex, passive smoking, attendance of a day-care centre or stay in nursery, prematurity, exclusive breastfeeding and large number of siblings. Conclusion: The identification of those risk factors will help put in place appropriate measures to reduce AOM prevalence in Parakou.
\end{abstract}

\section{Keywords}

Acute Otitis Media, Prevalence, Risk Factors, Children

\section{Introduction}

Acute otitis media (AOM) is one of the most common ENT diseases among children. About $62 \%$ of children

${ }^{*}$ Corresponding author.

How to cite this paper: Hounkpatin, S.H.R., Adedemy, J.D., Flatin, M.C., Awassi, S.F.E., Afouda, S.L., Avakoudjo, F., Adjbabi, W. and Vodouhè, S.J. (2016) Risk Factors for Acute Otitis Media in Children Aged 0 to 5 Years in Parakou. International Journal of Otolaryngology and Head \& Neck Surgery, 5, 73-78. http://dx.doi.org/10.4236/ijohns.2016.52012 
under one year of age and 83\% of children under three years have already had at least one acute otitis media [1]. Several risk factors for occurrence of AOM were identified, particularly in developed countries [2] [3]. Some are unanimously recognized as allergy, craniofacial malformations, iron deficiency, passive smoking and hypertrophy adenoids; other risk factors are more controversial as male or poor socio-economic conditions [1]. Studies conducted to determine risk factors for otitis media specific to Africa are not common in the literature; da Costa et al. in Maputo, Mozambique had reported that the use of smoke from coal and wood for cooking was a risk factor [4].

In Parakou, acute otitis media cases represented one of the most common ENT disorders in the Regional Hospital of Borgou (CHD-B) [5]. Those diseases affected the youngest subjects, with a high frequency between zero and five years.

This study aimed to investigate risk factors for acute otitis media in the Local government of Parakou among children aged 0 to 5 years.

\section{Methods}

This work was a cross-sectional, descriptive and analytical study; it was carried out from March 1 to May 31, 2011 among 0 - 5-year-old children in the 3 districts of the municipality of Parakou located in the North-East of Benin.

We undertook a two-stage cluster random sampling in the three (3) districts of the municipality of Parakou, with the administrative area as cluster unit. Households were randomly selected (through bottle collection method). Sample size was determined through the SCHWARTZ formula: $N=e \varepsilon_{\alpha}^{2} p q / i^{2}$

$N$ : sample size;

$e$ : cluster effect

$\varepsilon \alpha=$ standard reduces the risk $\alpha$

$\alpha=$ accepted risk of error (5\%)

$i$ : accuracy

$p$ : the prevalence of otitis media;

$q=1-\mathrm{p}$

The study variables were:

- $\quad$ descriptive and sociodemographic variables: their socioeconomic status was estimated according to type of house and hygienic conditions of the premises, domestic property and household's means of transport;

- $\quad$ child anthropometric data (weight-for-height ratio was estimated in Z-Score and used to identify children's nutritional status; hence, a Z-Score $\leq-3$ was considered as severe acute malnutrition (SAM), a Z-Score $>$ -3 and $\leq-2$ moderate acute malnutrition, and a Z-Score $>-2$ absence of malnutrition),

- $\quad$ personal and family health history and clinical examination results.

In total 18 variables were investigated: [age, sex, parents' occupation, socioeconomic status, number of children in the household, stay in nursery, child educational status (attendance or not of a day-care centre), passive smoking, source of heat used for cooking, exposure to charcoal and wood smoke, Z-Score, personal otitis history, otitis history among the siblings, type of breastfeeding, duration of breastfeeding, weaning age, use of baby bottle, traditional gavage feeding for baby and nutritional status.

Data were collected among children's parents interviewed by a team of three people: the interviewer, the supervisor and a language translator.

The interview was direct and structured by means of a questionnaire submitted to the children to be investigated's parents. The medical examination which consisted of an interview in search of history of ENT diseases or current morbidity and of physical examination in search of middle-ear infection was essentially otoscopy. The diagnostic of acute otitis media was adopted based on interview data and eardrum aspect or otoscopy.

The data were processed with Epi info 3.2 soft ware and Excel 2007. Pearson's chi-square and Odd Ratio (OR) served to identify statistically significant relationships between factors and occurrence of acute otitis media. The threshold for statistical significance $(\alpha)$ was set at $5 \%$.

Only the factors for which a statistically significant relationship with acute otitis media $(\mathrm{p}<0.05)$ was found were taken into account for discussion within the framework of this article.

A limitation of the study was the lack of diagnostic tests to explore some potential factors, such as iron deficiency. 


\section{Results}

The survey focused on 2040 children meeting our criteria in the three districts of Parakou.

Acute otitis media (AOM) was diagnosed in 58 of them, i.e. a frequency of $2.84 \% \mathrm{CI}_{95 \%}[0.021 ; 0.036]$ during the study period.

A personal history of AOM was identified in 332 children, including 48 among the 58 cases diagnosed on the basis of interview and health records; this corresponds to a $16.27 \%$ prevalence with $\mathrm{CI}_{95 \%}=[0.142-0.182]$.

\subsection{Age and Sex}

The mean age of the 2040 children interviewed was 2.22 years with extremes of 1 day and 5 years. Among them, 1035 were male (50.7\%) and 1005 female (49.3\%).

\subsection{Socioeconomic Status}

Socioeconomic status was assessed as low in $40 \%$ of households, average in $57 \%$ and high in $3 \%$. The socioeconomic status of the households to which belonged 58 children with acute otitis media, was low for 33 children (56.9\%), average for 24 children (41.4\%) and high for 01 child i.e. $1.7 \%$.

\subsection{Source of Heat Used for Cooking in Children's Households}

Among the 2040 children interviewed, 2035 i.e. 99.8\% were from households where the source of heat used for cooking was wood or charcoal fire. One Thousand Seven Hundred Twenty-Seven (1727) of them i.e. 84.7\% often helped their mums in the kitchen (the youngest ones are carried on the back of their mothers).

All the 58 children with otitis belonged to households where charcoal and wood furnaces were used for food cooking and 56 of them (96.6\%) were exposed to smoke generated by those furnaces since they often help their mother in the kitchen.

\subsection{History of Otitis}

Two hundred and seventy-four (274) children had personal history of otitis, including 48 of those who suffered from it during the survey period and 796 had personal history of repeated cases of rhinitis, including 44 of the ones who had otitis.

Two hundred and sixty (260) children had personal history of otitis, among their siblings, including 32.7\% of those who suffered from it during the survey period.

\subsection{Nutritional Status}

No case of malnutrition was found in 1344 (67.3\%) of the children, including 29 of those who had otitis. Moderate malnutrition was identified in 369 (18.9\%) children, including 16 of those who had otitis and severe malnutrition in 269 children (13.8\%), including 13 of those who had otitis.

\subsection{Relationship between Risk Factors and Occurrence of Otitis}

The various risk factors found are summarized in Table 1 which specifies for each factor its frequency in both groups (children with or children without otitis), the significance level (p) and the odd of developing otitis.

\section{Discussion}

Studies on AOM frequency and prevalence are not common in the literature, except in the United States of America.

In 2002, in a study conducted in Saudi Arabia, 40 cases of suppurative AOM were diagnosed in 1108 children aged under 4 years; this corresponds to a 3.61\% frequency [6]. An 8.6\% frequency of AOM was reported in India in 2011among a population of preschool-aged children [7]. In Parakou, AOM frequency was lower (2.8\%).

In the USA, AOM are among the most common infectious diseases in children under 5 years of age, with a prevalence varying from $50 \%$ to $80 \%$ [8] [9]. French authors also reported a variation in AOM prevalence between $50 \%$ and $85 \%$ [1] [10]. It was not possible for us to find in the literature data on AOM prevalence in 
Table 1. Statistical relationship of acute otitis media with the study variables.

\begin{tabular}{|c|c|c|c|c|c|}
\hline & Otitis $\left(n_{1}=58\right)$ & No otitis $\left(n_{2}=1982\right)$ & Total & $\mathrm{p}$ & OR (CI 95\%) \\
\hline \multicolumn{6}{|c|}{ Socioeconomic status $(n=2040)$. } \\
\hline High & 01 & 60 & 61 & \multirow{3}{*}{0.027} & 1 \\
\hline Average & 24 & 1140 & 1164 & & $1.26[0.43-1.19]$ \\
\hline Low & 33 & 782 & 815 & & $2.53[0.91-2.27]$ \\
\hline \multicolumn{6}{|c|}{ Exposure or not of child to charcoal or wood smoke $(n=2040)$} \\
\hline No exposure & 02 & 311 & 313 & \multirow{2}{*}{0.010} & 1 \\
\hline Exposure & 56 & 1671 & 1727 & & $5.22[0.78-1.69]$ \\
\hline \multicolumn{6}{|c|}{ Recurrent or chronic rhinitis $(n=2040)$} \\
\hline No & 14 & 1230 & 1244 & \multirow{2}{*}{0.000} & 1 \\
\hline Yes & 44 & 752 & 796 & & $5.13[1.31$ - 3.04] \\
\hline \multicolumn{6}{|c|}{ Personal history of otitis $(n=2040)$} \\
\hline No & 10 & 1708 & 1718 & \multirow{2}{*}{0.000} & 1 \\
\hline Yes & 48 & 274 & 322 & & $29.95[3.93-9.13]$ \\
\hline \multicolumn{6}{|c|}{ Otitis among the siblings $(n=2040)$} \\
\hline No & 39 & 1722 & 1761 & \multirow{2}{*}{0.000} & 1 \\
\hline Yes & 19 & 260 & 279 & & 3.24 [1.41 - 4.38] \\
\hline \multicolumn{6}{|c|}{ Nutritionalstatus $(n=2040)$} \\
\hline No malnutrition & 29 & 1344 & 1373 & & 1 \\
\hline Moderate malnutrition & 16 & 369 & 385 & 0.016 & $2[0.81-2.68]$ \\
\hline Severe malnutrition & 13 & 269 & 282 & & $2.23[0.85-3.15]$ \\
\hline
\end{tabular}

$n_{1}$ : cases of acute otitis media diagnosed (AOM); $n_{2}$ : children with no AOM; n: total of children interviewed.

Africa. The scarcity of epidemiological studies on AOM in developing countries had also been mentioned by others researchers [6] [11]. In the Local government of Parakou, we estimated AOM prevalence at 16.27\%. This rate is much lower than those reported in the USA and France. This difference may be due to many reasons, including racial group. In fact, although this is still being discussed, black children would have less otitis media than white children. Vernacchio et al. demonstrated in a cohort study focused on 11349 children and taking into account social disparities, that Black and Asian children were less likely to have otitis media than white children (Caucasian). However, the reasons why there is such a racial disparity remain unknown [12]. Another cause of that low prevalence of AOM in Parakou may be the fact that children in Africa are often on the back of their mother. This position of the child prevents transit of nasopharynx secretions to tympanic cavity through Eustachian tube which is straight and open at that age, this is not the case when child lies down in a baby pram or stroller.

As far as socioeconomic status is concerned, studies did not identify any relationship between socioeconomic status and otitis media [1] [13] [14]. By contrast, other research works reported that the disease is more common in households with low socioeconomic status [15] [16]. In this study, an association was identified between low socioeconomic status and occurrence of AOM. For instance, it appears that children from household with low socioeconomic status run 1.73 times the risk of developing an AOM. This may be caused by unhygienic conditions of the environment in which children from such households live, as is the case for Parakou.

Cooking with charcoal or wood fire is very spread in Parakou. Like in Maputo in the study of da Costa et al [4], there was a high correlation between exposure to charcoal or wood smoke and occurrence of acute otitis media in children in Parakou (OR 5.22 CI $_{95 \%} 1.24$ - 31.02). According to a study carried out in 2006 by Brauer et al on the relationship between vehicles exhaust gas and occurrence of otitis media among populations of German and Dutch children, the estimation of air pollutants in houses of about 4000 infants in whom AOM was diagnosed before 2 years of age, was made and it helped conclude that there is a reliable but significant relationship between pollutants and otitis media [17]. The estimation of suspended particles in kitchens in Parakou 
could have not been done but according to statistical tests, children exposed to wood and charcoal smoke had 5.22 times more risk of developing AOM than those who were not exposed. Charcoal and wood are the main sources of energy for cooking in several households in the Local government of Parakou and $99.8 \%$ of the study target children belonged to such households; however, all of them did not help their mothers in the kitchen on a regular basis. That source of heat is currently three times cheaper than gas; but both have relatively the same durations of use.

An association between recurrent cases of rhinitis and AOM was also pointed out in this study. Indeed, children with chronic rhinitis had 5.13 times more risk $\left(\mathrm{CI}_{95 \%} 1.31\right.$ - 3.04) of developing AOM than those who did not have it. The persistence of rhinitis cases probably increases the possibility of migration of bacteria in secretions of nasal cavity and nasopharynx to tympanic cavity through Eustachian tube. An epidemiological study carried out in 2010 among preschool-aged children in the South of India found out that persistence of rhinorrhea, a common problem in $10 \%$ of children from that region, was an important risk factor for AOM [7].

The results of this research work also conclude that AOM history is an important risk factor for occurrence of new outbreak of AOM. Actually, children with personal history of otitis were 29.95 times more exposed to the risk of having it again than those who did not have that health history ( $\mathrm{IC}_{95 \%} 3.93$ - 9.13). We also identified a strong association between history of otitis among the siblings and occurrence of AOM. Risk was 3.24 times higher in children with brothers and sisters who experienced occurrences of $\mathrm{AOM}$ ( $\mathrm{CI}_{95 \%} 1.41$ - 4.38). Those associations may be due to genetic predisposition or exposure to the same environmental risk factor shared by the family members. Joost $e t$ al. also found an association between otitis occurrence and family history of otitis [18].

Out of the 2040 children interviewed, 667 i.e. $32.7 \%$ had global acute malnutrition (GAM), including 18.9\% of moderate acute malnutrition (MAM) and 13.8\% of severe acute malnutrition (SAM) without complication. Severe malnutrition may be a factor for exposure to occurrence of AOM, for although CI does not allow us to claim it, children with a severe acute malnutrition (SAM) were 2.23 times more exposed to the risk of developing AOM than those who had good nutritional status and those who had a moderate acute malnutrition (MAM) were 2 times more exposed to risk than those who were not exposed $(p=0.01)$. This may be justified by the fact that malnutrition results in weaker human body's immune defense. Da Costa et al. found a similar result in Mozambique in 2004, like Alabi et al. in Nigeria in 2009 [4] [11].

\section{Conclusion}

Several risk factors were identified in the Local government of Parakou among 0 - 5-year-old children. The knowledge of such factors enables to take measures so as to limit the occurrence of otitis. Programs and policies for information, education and sensitization of the population of Parakou should be undertaken in collaboration with political and administrative authorities in order to modify those factors as much as possible.

\section{References}

[1] Baculard, F. (2007) Epidemiology of Acute Otitis Media and Its Complications in the Child. Médecine thérapeutique/ Pédiatrie, 10, 154-157.

[2] Uhari, M., Mantysaari, K. and Niemela, M. (1996) A Meta-Analytic Review of the Risk Factors for Acute Otitis Media. Clinical Infectious Diseases, 22, 1079-1083. http://dx.doi.org/10.1093/clinids/22.6.1079

[3] Daly, K.A., Brown J.E., Lindgren, B.R., Meland, M.H., Le, C.T. and Giebink, G.S. (1999) Epidemiology of Otitis Media Onset by Six Months of Age. Pediatrics, 103, 1158-1166. http://dx.doi.org/10.1542/peds.103.6.1158

[4] da Costa, J.L., Navarro, A., Neves, J.B. and Martin, M. (2004) Household Wood and Charcoal Smoke Increases the Risk of Otitis Media in Childhood in Maputo. International Journal of Epidemiology, 33, 573-578. http://dx.doi.org/10.1093/ije/dyh071

[5] Hounkpatin, S.H.R., Avakoudjo, F., Lawson Afouda, S., Yemadjro, F.S.R., Adjibabi, W. and Vodouhè, S.J. (2011) Prevalence of ENT Disorders in the Borgou Regional Hospital in the North-Benin. La Revue africaine d'ORL et de Chirurgie cervico-faciale, 11, 47-51.

[6] Zakzouk, S.M., Jamal, T.S. and Daghistani, K.J. (2002) Epidemiology of Acute Otitis Media among Saudi Children. International Journal of Pediatric Otorhinolaryngology, 62, 219-222. http://dx.doi.org/10.1016/S0165-5876(01)00617-6

[7] Sophia, A., Rita, I., Rebekah, G., Brahmadathan, K. and Rupa, V. (2010) Risk Factors for Otitis Media among Preschool, Rural Indian Children. International Journal of Pediatric Otorhinolaryngology, 74, 677-683. http://dx.doi.org/10.1016/j.ijporl.2010.03.023 
[8] Rovers, M.M., et al. (2004) Otitis Media. Lancet, 363, 465-473. http://dx.doi.org/10.1016/S0140-6736(04)15495-0

[9] Coco, A., Vernacchio, L., Horst, M. and Andersona, A. (2010) Management of Acute Otitis Media after Publication of the 2004 AAP and AAFP Clinical Practice Guideline. Pediatrics, 125, 214-220. http://dx.doi.org/10.1542/peds.2009-1115

[10] Lescanne, E., Lanotte, P., Pondaven, S. and Autret-Leca, E. (2005) Otites moyennes aiguës. Encycl Méd Chir (Elsevier SAS, Paris), Oto-Rhino-Laryngologie, 20-135-A-10, 1-11. http://s3.amazonaws.com/publicationslist.org/data/emmanuel.lescanne/ref-28/Lescanne_OMA.pdf

[11] Alabi, B., Abdulkarim, A.A., Olatoke, F. and Suleiman, O.A. (2009) Prevalence of Acute Otitis Media among Children with Pyrexia in a Nigerian Hospital. Auris Nasus Larynx, 36, 532-535. http://dx.doi.org/10.1016/j.anl.2008.12.007

[12] Vernacchio, L., Lesko, S.M. and Vezina, R.M. (2004) Racial/Ethnic Disparities in the Diagnosis of Otitis Media in Infancy. Int J PediatrOtorhinolaryngol, 68, 795-804. http://dx.doi.org/10.1016/j.ijporl.2004.01.012

[13] Wood, C.R. (2003) Lack of Association of Race/Ethnicity and Otitis Media in the First Two Years of Life. Clin. Paediatr, 42, 687-696. http://dx.doi.org/10.1177/000992280304200804

[14] Niemella, M., Uhari, M. and Mottonen, M. (1995) A Pacifier Increases the Risk of Recurrent Acute Otitis Media in Children in Day Care Centres. Paediatrics, 96, 884-888.

[15] Casselbrant, M.L. and Mandel, E.M. (2003) Epidemiology. In: Rosenfeld, R.M. and Bluestone, C.D., Eds., Evidence-Based Otitis Media, 2nd Edition, BC Decker, Hamilton, 147-162.

[16] Daly, K.A., Hoffman, H.J., Kvaerner, K.J., Kvestad, E., Casselbrant, M.L., Homoe, E.T.P., et al. (2011) Epidemiology, Natural History, and Risk Factors: Panel Report from the Ninth International Research Conference on Otitis Media. International Journal of Pediatric Otorhinolaryngology, 74, 231-240. http://dx.doi.org/10.1016/j.ijporl.2009.09.006

[17] Brauer, M., Gehring, U., Brunekreef, B., de Jongste, J., Gerritsen, J., Rovers, M., et al. (2006) Traffic-Related Air Pollution and Otitis Media. Environmental Health Perspectives, 114, 1414-1418. http://dx.doi.org/10.1289/ehp.9089

[18] Joost, A.M., Liesbeth, D., Ankie, L., de Groot, R., Hofman, A., Vincent, V.W., et al. (2011) Risk Factors for Otitis Media in Children with Special Emphasis on the Role of Colonization with Bacterial Airway Pathogens: The Generation R Study. European Journal of Epidemiology, 26, 61-66. http://dx.doi.org/10.1007/s10654-010-9500-2 